\title{
Positive Solutions for Third-Order Boundary-Value Problems with the Integral Boundary Conditions and Dependence on the First-Order Derivatives
}

\author{
Yanping Guo ${ }^{1}$ and Fei Yang ${ }^{2}$ \\ ${ }^{1}$ School of Electrical Engineering, Hebei University of Science and Technology, Shijiazhuang, Hebei 050018, China \\ ${ }^{2}$ Nanchang Institute of Science and Technology, Nanchang, Jiangxi 330108, China \\ Correspondence should be addressed to Fei Yang; feixu126@126.com
}

Received 8 April 2013; Revised 2 June 2013; Accepted 9 June 2013

Academic Editor: Wei-Shih Du

Copyright (C) 2013 Y. Guo and F. Yang. This is an open access article distributed under the Creative Commons Attribution License, which permits unrestricted use, distribution, and reproduction in any medium, provided the original work is properly cited.

By using a fixed point theorem in a cone and the nonlocal third-order BVP's Green function, the existence of at least one positive solution for the third-order boundary-value problem with the integral boundary conditions $x^{\prime \prime \prime}(t)+f\left(t, x(t), x^{\prime}(t)\right)=0, t \in J$, $x(0)=0, x^{\prime \prime}(0)=0$, and $x(1)=\int_{0}^{1} g(t) x(t) d t$ is considered, where $f$ is a nonnegative continuous function, $J=[0,1]$, and $g \in L[0,1]$. The emphasis here is that $f$ depends on the first-order derivatives.

\section{Introduction}

Third-order boundary-value problems for differential equation play a very important role in a variety of different areas of applied mathematics and physics. Recently, third-order boundary-value problems have been many scholars' research object. For example, heat conduction, chemical engineering, underground water flow, thermoelasticity, and plasma physics can produce boundary-value problems with integral boundary conditions [1-3]. For more information about the general theory of integral equations and their relation with boundary-value problems, we refer readers to the books of Corduneanu [4] and Agarwal and O'Regan [5].

Moreover, boundary-value problems with integral boundary conditions constitute a very interesting and important class of problems. They include two, three, multipoint, and nonlocal boundary-value problems as special cases. Such kind of BVPs in Banach space has been studied by some researchers [6-8].

By the fixed point index theory in cones [9], Zhang et al. [10] investigated the multiplicity of positive solutions for a class of nonlinear boundary-value problems of fourthorder differential equations with integral boundary conditions in ordered Banach spaces. Feng et al. [11] investigated the existence and multiplicity of positive solutions for a class of nonlinear boundary-value problems of second-order differential equations with integral boundary conditions in ordered Banach spaces. Guo et al. [12] investigated the existence of positive solutions for the third-order boundary-value problems with integral boundary conditions and dependence on the second derivatives. In [13], by using the fixed point theorem of cone expansion and compression of norm type, Zhang and Ge proved the existence and multiplicity of symmetric positive solutions for the fourth-order boundaryvalue problems with integral boundary conditions. By using Krasnoselskii's fixed point theorem, Wang et al. [14] investigated the existence and nonexistence of positive solutions for a class of fourth-order nonlinear differential equation with integral boundary conditions

$$
\begin{aligned}
& x^{(4)}(t)=\omega(t) f\left(t, x(t), x^{\prime \prime}(t)\right), \quad 0<t<1, \\
& x(0)=\int_{0}^{1} h_{1}(s) x(s) d s, \\
& x(1)=\int_{0}^{1} k_{1}(s) x(s) d s, \\
& x^{\prime \prime}(0)=\int_{0}^{1} h_{2}(s) x^{\prime \prime}(s) d s, \\
& x^{\prime \prime}(1)=\int_{0}^{1} k_{2}(s) x^{\prime \prime}(s) d s,
\end{aligned}
$$


where the arguments are based on Krasnoselskii's fixed point theorem for operators on a cone.

However, Zhao et al. [15] investigated the following third-order boundary-value problem with integral boundary conditions:

$$
\begin{gathered}
x^{\prime \prime \prime}(t)+f(t, x(t))=\theta, \quad t \in J, \\
x(0)=\theta, \quad x^{\prime \prime}(0)=\theta, \\
x(1)=\int_{0}^{1} g(t) x(t) d t,
\end{gathered}
$$

under the assumptions

(1) $J=[0,1]$, and $\theta$ is the zero element of $E$,

(2) $f: C([0,1] \times P, P)$, and $g \in L[0,1]$ is nonnegative,

where $P$ is a cone in the real Banach $E$.

All the above works were done under the assumption that the first-order derivative $x^{\prime}$ is not involved explicitly in the nonlinear term $f$. In this paper, we are concerned with the existence of positive solutions for the third-order boundaryvalue problem with the integral boundary conditions

$$
\begin{gathered}
x^{\prime \prime \prime}(t)+f\left(t, x(t), x^{\prime}(t)\right)=0, \quad t \in J, \\
x(0)=0, \quad x^{\prime \prime}(0)=0, \\
x(1)=\int_{0}^{1} g(t) x(t) d t .
\end{gathered}
$$

Throughout, we assume

$$
\begin{array}{r}
\left(H_{1}\right) J=[0,1], f:[0,1] \times R^{2} \rightarrow R^{+} \text {is continuous, } g \in \\
L[0,1], g(t) \geq 0, \text { and } \sigma \in[0,1), \text { where } \sigma=\int_{0}^{1} s g(s) d s .
\end{array}
$$

To show the existence of positive solutions for (3), we define two positive continuous convex functionals. Then, by using the fixed point theorem [16] in a cone and the nonlocal third-order BVP's Green function, we give some new criteria for the existence of positive solutions for (3).

\section{Preliminaries}

Let $Y=C[0,1]$ be the Banach space equipped with the norm $\|x\|_{0}=\max _{t \in[0,1]}|x(t)|$.

Lemma 1 (see [15]). Suppose $\left(H_{1}\right)$ holds. Then for any $y(t) \epsilon$ $C[0,1]$, the problem

$$
\begin{gathered}
x^{\prime \prime \prime}(t)+y(t)=0, \quad t \in J, \\
x(0)=0, \quad x^{\prime \prime}(0)=0, \\
x(1)=\int_{0}^{1} g(t) x(t) d t
\end{gathered}
$$

has a unique solution

$$
x(t)=\int_{0}^{1} H(t, s) y(s) d s
$$

where

$$
\begin{gathered}
H(t, s)=G(t, s)+\frac{t}{1-\sigma} \int_{0}^{1} G(\tau, s) g(\tau) d \tau, \\
G(t, s)= \begin{cases}\frac{1}{2} t(1-s)^{2}-\frac{1}{2}(t-s)^{2}, & 0 \leq s \leq t \leq 1, \\
\frac{1}{2} t(1-s)^{2}, & 0 \leq t \leq s \leq 1 .\end{cases}
\end{gathered}
$$

Lemma 2 (see [15]). For $t, s \in[0,1]$, one has $0 \leq G(t, s) \leq$ $\max _{0 \leq t, s \leq 1} G(t, s) \leq 1 / 8$.

Remark 3. When $t, s \in(0,1)$, it is easy to check that $G(t, s)>$ 0 .

In addition, for $0 \leq s \leq t \leq 1$, the maximum of $G(t, s)$ occurs at $t=\left(1+s^{2}\right) / 2$.

Lemma 4 (see $[15])$. Choose $\delta \in(0,1 / 2)$ and $J_{\delta}=[\delta, 1-\delta]$; then for all $t \in J_{\delta}, v, s \in[0,1]$, one has

$$
G(t, s) \geq \rho G(v, s),
$$

where $\rho=4 \delta^{2}(1-\delta)$.

Remark 5. For $0 \leq s \leq t \leq 1$, denote $G(t, s)=G_{1}(t, s)$. Notice that $G_{1}(t, s)$ is concave with respect to $t$; we have

$$
\begin{aligned}
\min _{t \in J_{\delta}, 0 \leq s \leq t} G_{1}(t, s) & =\min \left\{G_{1}(\delta, s), G_{1}(1-\delta, s)\right\} \\
& =\frac{1}{2} \delta^{2}(1-\delta) .
\end{aligned}
$$

Lemma 6 (see $[15])$. Assume that $\left(H_{1}\right)$ holds; then

(i) $H(t, s) \leq(1 / 2) \gamma, t \in[0,1]$,

(ii) $H(t, s) \geq \rho H(v, s), t \in J_{\delta}, v, s \in[0,1]$,

where $\gamma=\left(1+\int_{0}^{1}(1-s) g(s) d s\right) /(1-\sigma)$.

Lemma 7. If $y \in C[0,1], y(t) \geq 0$, then the unique solution $x(t)$ of problem (4) satisfies

$$
\min _{t \in J_{\delta}} x(t) \geq \rho\|x\|_{0}
$$

Proof. By Lemmas 4 and 6 and (5), we get

$$
\begin{aligned}
\min _{t \in J_{\delta}} x(t) & =\min _{t \in J_{\delta}} \int_{0}^{1} H(t, s) y(s) d s \\
& \geq \rho \int_{0}^{1} H(v, s) y(s) d s \\
& \geq \rho x(v) .
\end{aligned}
$$

For $v \in[0,1]$, we have

$$
\min _{t \in J_{\delta}} x(t) \geq \rho x(v) .
$$

So,

$$
\min _{t \in J_{\delta}} x(t) \geq \rho \max _{v \in[0,1]} x(v)=\rho \max _{v \in[0,1]}|x(v)|=\rho\|x\|_{0} .
$$

The proof is completed. 
Let $X$ be a Banach space and $K \subset X$ a cone. Suppose $\alpha, \beta$ : $X \rightarrow R^{+}$are two continuous convex functionals satisfying $\alpha(\lambda x)=|\lambda| \alpha(x), \beta(\lambda x)=|\lambda| \beta(x)$, for $x \in X, \lambda \in R,\|x\| \leq$ $M \max \{\alpha(x), \beta(x)\}$, for $x \in X$, and $\alpha(x) \leq \alpha(y)$ for $x, y \in K$, $x \leq y$, where $M>0$ is a constant.

Theorem 8 (see [16]). Let $r_{2}>r_{1}>0, L>0$ be constants and

$$
\Omega_{i}=\left\{x \in X: \alpha(x)<r_{i}, \beta(x)<L\right\}, \quad i=1,2,
$$

two bounded open sets in X. Set

$$
D_{i}=\left\{x \in X: \alpha(x)=r_{i}\right\}, \quad i=1,2 .
$$

Assume $T: K \rightarrow K$ is a completely continuous operator satisfying

$\left(A_{1}\right) \alpha(T x)<r_{1}, x \in D_{1} \cap K ; \alpha(T x)>r_{2}, x \in D_{2} \cap K ;$

$\left(A_{2}\right) \beta(T x)<L, x \in K$

$\left(A_{3}\right)$ there is a $p \in\left(\Omega_{2} \cap K\right) \backslash\{0\}$ such that $\alpha(p) \neq 0$ and $\alpha(x+\lambda p) \geq \alpha(x)$, for all $x \in K$ and $\lambda \geq 0$.

Then $T$ has at least one fixed point in $\left(\Omega_{2} \backslash \bar{\Omega}_{1}\right) \cap K$.

\section{Main Results}

Let $X=C^{1}[0,1]$ be the Banach space equipped with the norm $\|x\|=\max _{t \in[0,1]}|x(t)|+\max _{t \in[0,1]}\left|x^{\prime}(t)\right|$, and $K=\{x \in X$ : $\left.x(t) \geq 0, \min _{t \in J_{\delta}} x(t) \geq \rho\|x\|_{0}\right\}$ is a cone in $X$.

Define two continuous convex functionals $\alpha(x)=$ $\max _{t \in[0,1]}|x(t)|$ and $\beta(x)=\max _{t \in[0,1]}\left|x^{\prime}(t)\right|$, for each $x \in X$; then $\|x\| \leq 2 \max \{\alpha(x), \beta(x)\}$ and $\alpha(\lambda x)=|\lambda| \alpha(x), \beta(\lambda x)=$ $|\lambda| \beta(x)$, for $x \in X, \lambda \in R ; \alpha(x) \leq \alpha(y)$ for $x, y \in K, x \leq y$.

In the following, we denote

$$
\begin{gathered}
\eta_{0}=\frac{1}{8}+\int_{0}^{1}\left[\frac{1}{1-\sigma} \int_{0}^{1} G(\tau, s) g(\tau) d \tau\right] d s, \\
\eta_{1}=\max _{v \in[0,1]} \int_{\delta}^{1-\delta} H(v, s) d s, \\
\eta_{2}=\frac{2}{3}+\int_{0}^{1}\left[\frac{1}{1-\sigma} \int_{0}^{1} G(\tau, s) g(\tau) d \tau\right] d s .
\end{gathered}
$$

We will suppose that there are $L>b>\rho b>c>0$ such that $f(t, x, y)$ satisfies the following growth conditions:

$\left(H_{2}\right) f(t, x, y)<c / \eta_{0}$, for $(t, x, y) \in[0,1] \times[0, c] \times[-L, L]$,

$\left(H_{3}\right) f(t, x, y) \geq b / \rho \eta_{1}$, for $(t, x, y) \in[\delta, 1-\delta] \times[\rho b, b] \times$ $[-L, L]$,

$\left(H_{4}\right) f(t, x, y)<L / \eta_{2}$, for $(t, x, y) \in[0,1] \times[0, b] \times[-L, L]$.
Let

$$
\begin{aligned}
& f^{*}(t, x, y) \\
& \quad=\left\{\begin{array}{l}
f(t, x, y),(t, x, y) \in[0,1] \times[0, b] \times(-\infty, \infty), \\
f(t, b, y),(t, x, y) \in[0,1] \times(b, \infty) \times(-\infty, \infty),
\end{array}\right. \\
& f_{1}(t, x, y) \\
& =\left\{\begin{array}{l}
f^{*}(t, x, y),(t, x, y) \in[0,1] \times[0, \infty) \times[-L, L], \\
f^{*}(t, x,-L),(t, x, y) \in[0,1] \times[0, \infty) \times(-\infty,-L], \\
f^{*}(t, x, L),(t, x, y) \in[0,1] \times[0, \infty) \times[L, \infty) .
\end{array}\right.
\end{aligned}
$$

We denote

$$
\begin{gathered}
(T x)(t)=\int_{0}^{1} H(t, s) f_{1}\left(s, x, x^{\prime}\right) d s \\
(T x)^{\prime}(t)=\int_{0}^{1} \frac{\partial H(t, s)}{\partial t} f_{1}\left(s, x, x^{\prime}\right) d s
\end{gathered}
$$

Lemma 9. Suppose $\left(H_{1}\right)$ holds. Then $T: K \rightarrow K$ is completely continuous.

Proof. For $x \in K$, by Lemmas 2 and 4, it is obviously that $T x \geq 0$.

By Lemma 7, we have

$$
\min _{t \in J_{\delta}} T x(t) \geq \rho\|T x\|_{0}
$$

So, we can get $T(K) \subset K$.

In the following, we will show that $T: K \rightarrow K$ is completely continuous.

At first we show that $T: K \rightarrow K$ is continuous.

Let $x_{n}, x^{*} \in K$, it satisfies $\left\|x_{n}-x^{*}\right\| \rightarrow 0,(n \rightarrow \infty)$, and then there is a constant $M_{0}>0$, such that $\max _{t \in[0,1]}$ $\left\{\left|x_{n}(t)\right|,\left|x^{*}(t)\right|,\left|x_{n}^{\prime}(t)\right|,\left|x^{*^{\prime}}(t)\right|\right\} \leq M_{0}$; then

$$
\begin{aligned}
& \left|\left(T x_{n}\right)(t)-\left(T x^{*}\right)(t)\right| \\
& =\mid \int_{0}^{1} H(t, s) f_{1}\left(s, x_{n}, x_{n}^{\prime}\right) d s \\
& \quad-\int_{0}^{1} H(t, s) f_{1}\left(s, x^{*}, x^{*^{\prime}}\right) d s \mid \\
& \leq \quad \int_{0}^{1} H(t, s)\left|f_{1}\left(s, x_{n}, x_{n}^{\prime}\right)-f_{1}\left(s, x^{*}, x^{*^{\prime}}\right)\right| d s, \\
& \left|\left(T x_{n}\right)^{\prime}(t)-\left(T x^{*}\right)^{\prime}(t)\right| \\
& =\mid \int_{0}^{1} \frac{\partial H(t, s)}{\partial t} f_{1}\left(s, x, x_{n}^{\prime}\right) d s \\
& \quad-\int_{0}^{1} \frac{\partial H(t, s)}{\partial t} f_{1}\left(s, x^{*}, x^{*^{\prime}}\right) d s \mid
\end{aligned}
$$




$$
\begin{aligned}
& \leq \int_{0}^{1}\left|\frac{\partial H(t, s)}{\partial t}\right|\left|f_{1}\left(s, x, x_{n}^{\prime}\right)-f_{1}\left(s, x^{*}, x^{*^{\prime}}\right)\right| d s \\
& <\int_{0}^{1}\left[\frac{1}{2}(1-s)^{2}+(1-s)\right] \\
& \quad \times\left|f_{1}\left(s, x, x_{n}^{\prime}\right)-f_{1}\left(s, x^{*}, x^{*^{\prime}}\right)\right| d s \\
& +\int_{0}^{1}\left[\frac{1}{1-\sigma} \int_{0}^{1} G(\tau, s) g(\tau) d \tau\right] \\
& \quad \times\left|f_{1}\left(s, x, x_{n}^{\prime}\right)-f_{1}\left(s, x^{*}, x^{*^{\prime}}\right)\right| d s .
\end{aligned}
$$

By $f$ which is uniformly continuous on $[0,1] \times\left[-M_{0}\right.$, $\left.M_{0}\right] \times\left[-M_{0}, M_{0}\right]$, we get

$$
\left\|T x_{n}-T x^{*}\right\| \longrightarrow 0, \quad(n \longrightarrow \infty) .
$$

Next we show that $T: K \rightarrow K$ is compact.

Let $B \subset K$ be bounded; then there is $M>0$, such that $\|x\| \leq M$. For $x \in B$, we have

$$
\begin{aligned}
|(T x)(t)|= & \left|\int_{0}^{1} H(t, s) f_{1}\left(s, x, x^{\prime}\right) d s\right| \\
& \leq \int_{0}^{1} \frac{1}{2} \gamma f_{1}\left(s, x, x^{\prime}\right) d s \\
& =\frac{1}{2} \int_{0}^{1} \frac{1+\int_{0}^{1}(1-s) g(s) d s}{1-\sigma} d s \times C^{*},
\end{aligned}
$$

where $C^{*}=\max \left\{\left|f_{1}\left(t, x, x^{\prime}\right)\right| ; t \in[0,1], x \in B\right\}$.

Consider

$$
\begin{aligned}
\left|(T x)^{\prime}(t)\right| & \left|\int_{0}^{1} \frac{\partial H(t, s)}{\partial t} f_{1}\left(s, x, x^{\prime}\right) d s\right| \\
= & \mid \int_{0}^{1}\left[\frac{\partial G(t, s)}{\partial t}+\frac{1}{1-\sigma} \int_{0}^{1} G(\tau, s) g(\tau) d \tau\right] \\
& \times f_{1}\left(s, x, x^{\prime}\right) d s \mid \\
< & \mid \int_{0}^{1}\left[\frac{1}{2}(1-s)^{2}+(1-s)\right] d s \\
& +\int_{0}^{1}\left[\frac{1}{1-\sigma} \int_{0}^{1} G(\tau, s) g(\tau) d \tau\right] d s \mid \times C^{*} \\
= & \left|\frac{2}{3}+\int_{0}^{1}\left[\frac{1}{1-\sigma} \int_{0}^{1} G(\tau, s) g(\tau) d \tau\right] d s\right| \times C^{*} .
\end{aligned}
$$

It is clear that $T(B)$ is a bounded set in $K$, because $H(t, s)$ is uniformly continuous on $[0,1] \times[0,1]$, for $\varepsilon>0$, there exists $\delta \in(0, \varepsilon)$, such that $\left|H\left(t_{1}, s\right)-H\left(t_{2}, s\right)\right|<\varepsilon$, and for $t_{1}$, $t_{2} \in[0,1],\left|t_{1}-t_{2}\right|<\delta$.
For $x \in B$, we have

$$
\begin{aligned}
\left|(T x)\left(t_{1}\right)-(T x)\left(t_{2}\right)\right| & \mid \int_{0}^{1} H\left(t_{1}, s\right) f_{1}\left(s, x, x^{\prime}\right) d s \\
& -\int_{0}^{1} H\left(t_{2}, s\right) f_{1}\left(s, x, x^{\prime}\right) d s \mid \\
\leq & \int_{0}^{1}\left|H\left(t_{1}, s\right)-H\left(t_{2}, s\right)\right| d s \times C^{*} \leq \varepsilon C^{*}, \\
= & \left|\int_{0}^{1} \frac{\partial H(t, s)}{\partial t}\right|_{t=t_{1}} f_{1}\left(s, x, x^{\prime}\right) d s \\
\leq & \frac{1}{2}\left|\left(t_{1}\right)-(T x)^{\prime}\left(t_{2}\right)\right| \\
& \quad-\left.\int_{0}^{1} \frac{\partial H(t, s)}{\partial t}\right|_{t=t_{2}} f_{1}\left(s, x, x^{\prime}\right) d s \mid \\
= & \left|\int_{0}^{1} \frac{\partial G(t, s)}{\partial t}\right|_{t=t_{1}} f_{1}\left(s, x, x^{\prime}\right) d s \\
& -\left.\int_{0}^{t_{2}} \frac{\partial G(t, s)}{\partial t}\right|_{t=t_{2}} f_{1}\left(s, x, x^{\prime}\right) d s \mid
\end{aligned}
$$

Therefore $T(B)$ is equicontinuous. Using the ArzelaAscoli theorem, a standard proof yields $T: K \rightarrow K$ which is completely continuous.

Theorem 10. Suppose $\left(H_{1}\right)-\left(H_{4}\right)$ hold. Then BVP (3) has at least one positive solution $x(t)$ satisfying

$$
c<\alpha(x)<b, \quad \beta(x)<L .
$$

Proof. Take

$$
\begin{aligned}
& \Omega_{1}=\left\{x \in X:|x(t)|<c,\left|x(t)^{\prime}\right|<L\right\}, \\
& \Omega_{2}=\left\{x \in X:|x(t)|<b,\left|x(t)^{\prime}\right|<L\right\},
\end{aligned}
$$

two bounded open sets in $X$, and

$$
D_{1}=\{x \in X: \alpha(x)=c\}, \quad D_{2}=\{x \in X: \alpha(x)=b\} .
$$

By Lemma 9, $T: K \rightarrow K$ is completely continuous, and there is a $p \in\left(\Omega_{2} \cap K\right) \backslash\{0\}$ such that $\alpha(p) \neq 0$ and $\alpha(x+\lambda p) \geq$ $\alpha(x)$ for all $u \in K$ and $\lambda \geq 0$. 


$$
\begin{gathered}
\text { By }\left(H_{2}\right) \text {, for } x \in D_{1} \cap K \text { and } \alpha(x)=c \text {, we get } \\
\begin{aligned}
\alpha(T x)= & \max _{t \in[0,1]}\left|\int_{0}^{1} H(t, s) f_{1}\left(s, x, x^{\prime}\right) d s\right| \\
= & \max _{t \in[0,1]} \mid \int_{0}^{1}\left[G(t, s)+\frac{t}{1-\sigma} \int_{0}^{1} G(\tau, s) g(\tau) d \tau\right] \\
< & \int_{0}^{1}\left[\max _{t \in[0,1]} G(t, s)+\frac{t}{1-\sigma} \int_{0}^{1} G(\tau, s) g(\tau) d \tau\right] \\
& \times f_{1}\left(s, x, x^{\prime}\right) d s \\
< & {\left[\int_{0}^{1} \frac{1}{8} d s+\int_{0}^{1}\left(\frac{t}{1-\sigma} \int_{0}^{1} G(\tau, s) g(\tau) d \tau\right) d s\right] } \\
\quad \times \frac{c}{\eta_{0}} & \times \frac{c}{\eta_{0}}=c . \\
= & \left.\frac{1}{8}+\int_{0}^{1}\left(\frac{t}{1-\sigma} \int_{0}^{1} G(\tau, s) g(\tau) d \tau\right) d s\right]
\end{aligned}
\end{gathered}
$$

By Lemma 7, for $x \in D_{2} \cap K$ and $\alpha(x)=b$, there is $x(t) \geq$ $\rho \alpha(x)=\rho b, t \in J_{\delta}$.

So, by $\left(H_{3}\right)$, we get

$$
\begin{aligned}
\alpha(T x) & =\max _{t \in[0,1]}\left|\int_{0}^{1} H(t, s) f_{1}\left(s, x, x^{\prime}\right) d s\right| \\
& >\int_{\delta}^{1-\delta} H(t, s) f_{1}\left(s, x, x^{\prime}\right) d s \\
& >\rho \int_{\delta}^{1-\delta} H(v, s) d s \times \frac{b}{\rho \eta_{1}} .
\end{aligned}
$$

For $v \in[0,1]$, we have

$$
\alpha(T x)>\rho \int_{\delta}^{1-\delta} H(v, s) d s \times \frac{b}{\rho \eta_{1}} .
$$

So,

$$
\alpha(T x)>\rho \max _{v \in[0,1]} \int_{\delta}^{1-\delta} H(v, s) d s \times \frac{b}{\rho \eta_{1}}=b .
$$

By $\left(H_{4}\right)$, for $x \in K$, we have

$$
\begin{aligned}
\beta(T x)=\max _{t \in[0,1]}\left|\int_{0}^{1} \frac{\partial H(t, s)}{\partial t} f_{1}\left(s, x, x^{\prime}\right) d s\right| \\
<\mid \int_{0}^{1}\left[\frac{\partial G(t, s)}{\partial t}+\frac{1}{1-\sigma} \int_{0}^{1} G(\tau, s) g(\tau) d \tau\right] \\
\quad \times f_{1}\left(s, x, x^{\prime}\right) d s
\end{aligned}
$$

$$
\begin{aligned}
& =\mid \int_{0}^{t}\left(\frac{1}{2}(1-s)^{2}-(t-s)\right) f_{1}\left(s, x, x^{\prime}\right) d s \\
& \quad+\int_{t}^{1} \frac{1}{2}(1-s)^{2} f_{1}\left(s, x, x^{\prime}\right) d s \\
& \quad+\int_{0}^{1}\left[\frac{1}{1-\sigma} \int_{0}^{1} G(\tau, s) g(\tau) d \tau\right] \\
& \quad \times f_{1}\left(s, x, x^{\prime}\right) d s \mid \\
& <\left[\int_{0}^{1}\left(\frac{1}{2}(1-s)^{2}+(1-s)\right) d s\right. \\
& \left.\quad+\int_{0}^{1}\left(\frac{1}{1-\sigma} \int_{0}^{1} G(\tau, s) g(\tau) d \tau\right) d s\right] \times \frac{L}{\eta_{2}} \\
& =\left[\frac{2}{3}+\int_{0}^{1}\left(\frac{1}{1-\sigma} \int_{0}^{1} G(\tau, s) g(\tau) d \tau\right) d s\right] \\
& \quad \times \frac{L}{\eta_{2}}=L .
\end{aligned}
$$

Theorem 8 implies there is $x \in\left(\Omega_{2} \backslash \bar{\Omega}_{1}\right) \cap K$ such that $x=T x$. So, $x(t)$ is a positive solution for BVP (3) satisfying

$$
c<\alpha(x)<b, \quad \beta(x)<L .
$$

Thus, Theorem 10 is completed.

\section{Example}

Example 1. Consider the following boundary-value problem

$$
\begin{gathered}
x^{\prime \prime \prime}(t)+f\left(t, x(t), x^{\prime}(t)\right)=0, \quad 0<t<1, \\
x(0)=0, \quad x^{\prime \prime}(0)=0, \\
x(1)=\int_{0}^{1} x(t) d t,
\end{gathered}
$$

where

$$
\begin{aligned}
& f(t, x, y) \\
& \quad=\left\{\begin{array}{l}
\frac{t}{3} x+2 x+|\cos y| \\
(t, x, y) \in[0,1] \times[0,0.5] \times[-3667,3667] \\
\frac{109 t}{3}(x-0.5)+25742(x-0.5)+\frac{t}{6}+1+|\cos y| \\
(t, x, y) \in[0,1] \times[0.5,0.6] \times[-3667,3667] \\
\frac{t}{3}(11-x)+222(x+11)+|\cos y| \\
(t, x, y) \in[0,1] \times[0.6,11] \times[-3667,3667]
\end{array}\right.
\end{aligned}
$$

In this problem, we know that $g(t)=1$; then we can get $\sigma=\int_{0}^{1} s g(s) d s=1 / 2$. Choose $\delta=1 / 8 \in(0,1 / 2)$; then $\rho=$ $4 \delta^{2}(1-\delta)=7 / 128$. 
Furthermore, we obtain

$$
\eta_{0}=\frac{5}{24}, \quad \rho \eta_{1}=\frac{35}{8192}, \quad \eta_{2}=\frac{3}{4} .
$$

If we take $c=0.5, b=11$, and $L=3667$, then we get $\rho b \approx 0.601>0.6$ :

$$
f(t, x, y)=\frac{t}{3} x+2 x+|\cos y| \leq 2.17<\frac{c}{\eta_{0}} \approx 2.4
$$

for $(t, x, y) \in[0,1] \times[0,0.5] \times[-3667,3667]$,

$$
\begin{aligned}
f(t, x, y)= & \frac{t}{3}(11-x)+222(x+11) \\
& +|\cos y| \geq 2575.2>\frac{b}{\rho \eta_{1}} \approx 2574.1,
\end{aligned}
$$

for $(t, x, y) \in[\delta, 1-\delta] \times[\delta b, 11] \times[-3667,3667]$,

$$
f(t, x, y) \leq 4888.8<\frac{L}{\eta_{2}} \approx 4889.3,
$$

for $(t, x, y) \in[0,1] \times[0,11] \times[-3667,3667]$.

Then all the conditions of Theorem 10 are satisfied. Therefore, by Theorem 10 we know that boundary-value problem (33) has at least one positive solution $x(t)$ satisfying

$$
0.5<\alpha(x)<11, \quad \beta(x)<3667 .
$$

\section{Acknowledgments}

The project is supported by the Natural Science Foundation of China (10971045) and the Natural Science Foundation of Hebei Province (A2013208147).

\section{References}

[1] J. M. Gallardo, "Second-order differential operators with integral boundary conditions and generation of analytic semigroups," The Rocky Mountain Journal of Mathematics, vol. 30, no. 4, pp. 1265-1291, 2000.

[2] G. L. Karakostas and P. Ch. Tsamatos, "Multiple positive solutions of some Fredholm integral equations arisen from nonlocal boundary-value problems," Electronic Journal of Differential Equations, vol. 2002, no. 30, pp. 1-17, 2002.

[3] A. Lomtatidze and L. Malaguti, "On a nonlocal boundary value problem for second order nonlinear singular differential equations," Georgian Mathematical Journal, vol. 7, no. 1, pp. 133-154, 2000.

[4] C. Corduneanu, Integral Equations and Applications, Cambridge University Press, Cambridge, UK, 1991.

[5] R. P. Agarwal and D. O'Regan, Infinite Interval Problems for Differential, Difference, and Integral Equations, Kluwer Academic Publishers, Dordtreht, The Netherlands, 2001.

[6] Y. Guo, W. Shan, and W. Ge, "Positive solutions for second-order $m$-point boundary value problems," Journal of Computational and Applied Mathematics, vol. 151, no. 2, pp. 415-424, 2003.

[7] B. Liu, "Positive solutions of a nonlinear four-point boundary value problems in Banach spaces," Journal of Mathematical Analysis and Applications, vol. 305, no. 1, pp. 253-276, 2005.
[8] Y.-L. Zhao and H.-B. Chen, "Existence of multiple positive solutions for $m$-point boundary value problems in Banach spaces," Journal of Computational and Applied Mathematics, vol. 215, no. 1, pp. 79-90, 2008.

[9] D. J. Guo and V. Lakshmikantham, Nonlinear Problems in Abstract Cones, vol. 5 of Notes and Reports in Mathematics in Science and Engineering, Academic Press, New York, NY, USA, 1988.

[10] X. Zhang, M. Feng, and W. Ge, "Existence results for nonlinear boundary-value problems with integral boundary conditions in Banach spaces," Nonlinear Analysis: Theory, Methods \& Applications, vol. 69, no. 10, pp. 3310-3321, 2008.

[11] M. Feng, D. Ji, and W. Ge, "Positive solutions for a class of boundary-value problem with integral boundary conditions in Banach spaces," Journal of Computational and Applied Mathematics, vol. 222, no. 2, pp. 351-363, 2008.

[12] Y. Guo, Y. Liu, and Y. Liang, "Positive solutions for the thirdorder boundary value problems with the second derivatives," Boundary Value Problems, vol. 2012, no. 34, pp. 1-9, 2012.

[13] X. Zhang and W. Ge, "Symmetric positive solutions of boundary value problems with integral boundary conditions," Applied Mathematics and Computation, vol. 219, no. 8, pp. 3553-3564, 2012.

[14] Q. Wang, Y. Guo, and Y. Ji, "Positive solutions for fourthorder nonlinear differential equation with integral boundary conditions," Discrete Dynamics in Nature and Society, vol. 2013, Article ID 684962, 10 pages, 2013.

[15] J. Zhao, P. Wang, and W. Ge, "Existence and nonexistence of positive solutions for a class of third order BVP with integral boundary conditions in Banach spaces," Communications in Nonlinear Science and Numerical Simulation, vol. 16, no. 1, pp. 402-413, 2011.

[16] Y. Guo and W. Ge, "Positive solutions for three-point boundary value problems with dependence on the first order derivative," Journal of Mathematical Analysis and Applications, vol. 290, no. 1, pp. 291-301, 2004. 


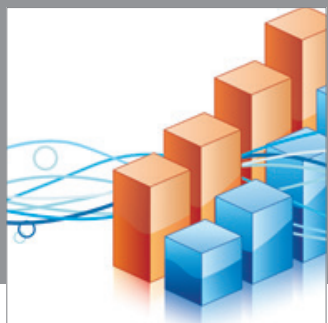

Advances in

Operations Research

mansans

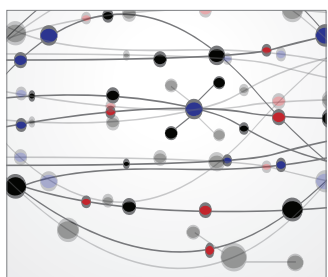

The Scientific World Journal
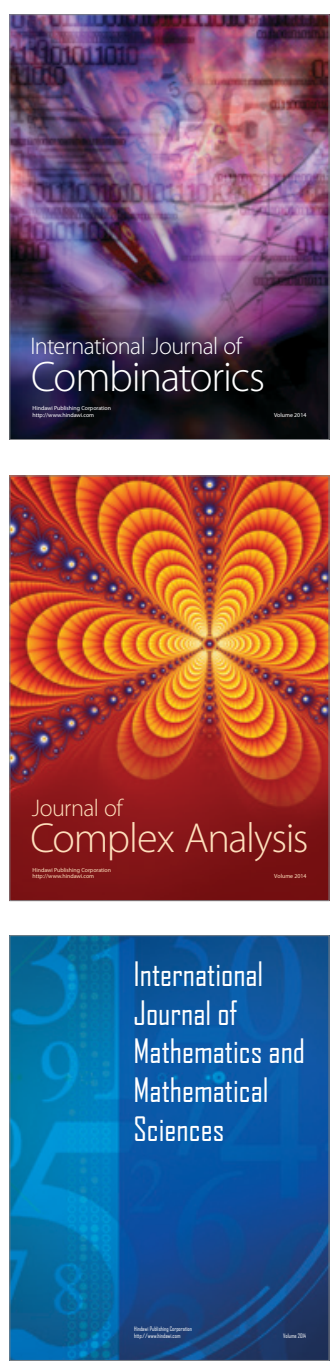
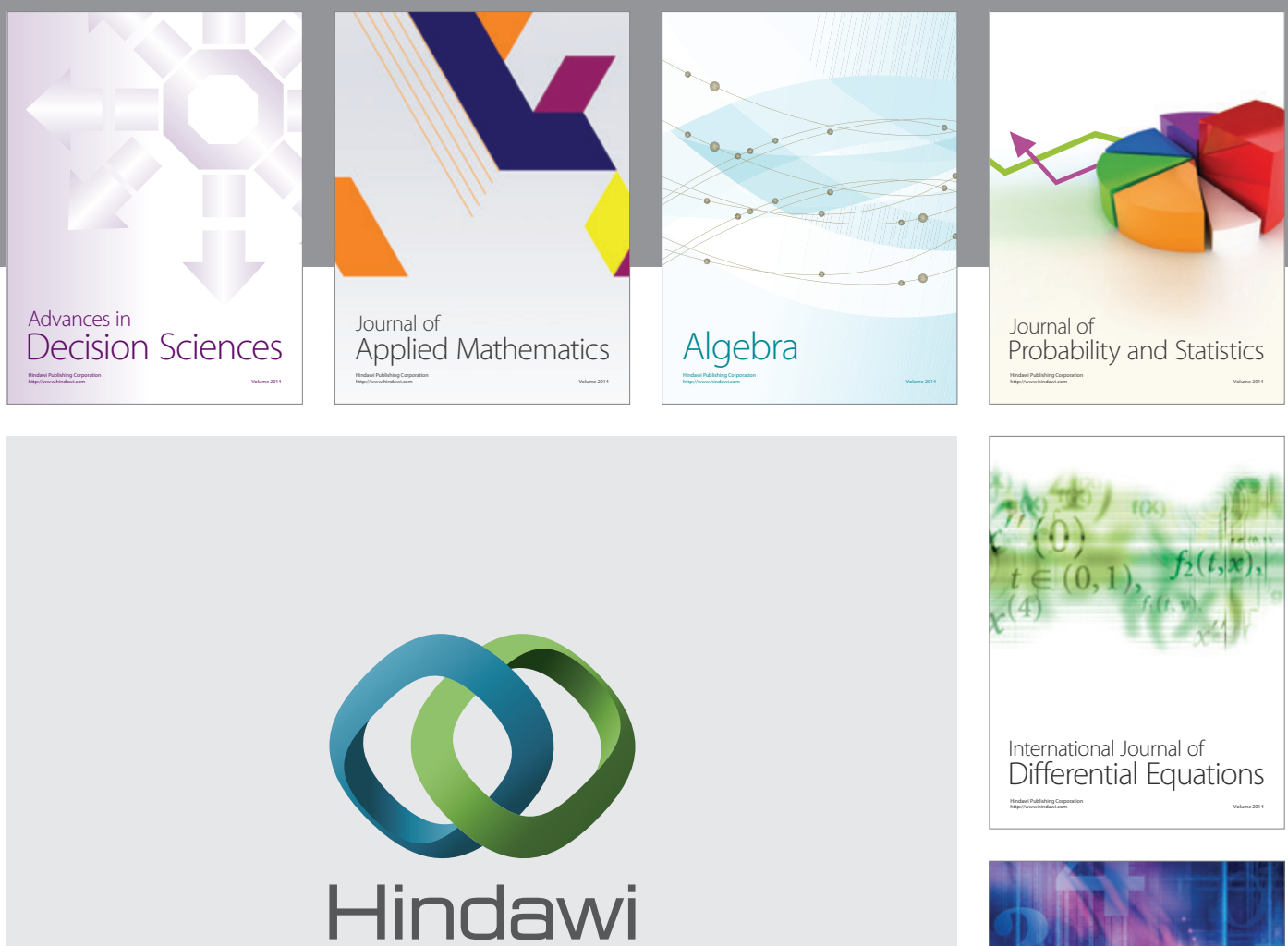

Submit your manuscripts at http://www.hindawi.com
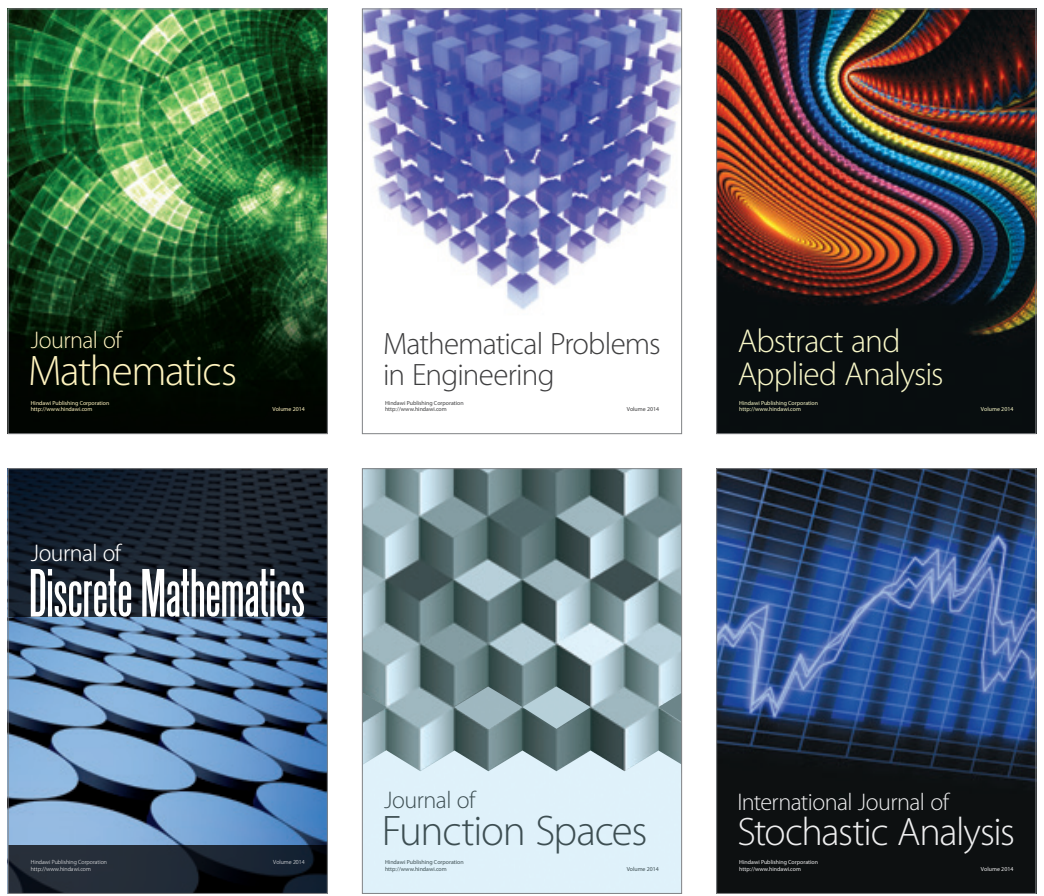

Journal of

Function Spaces

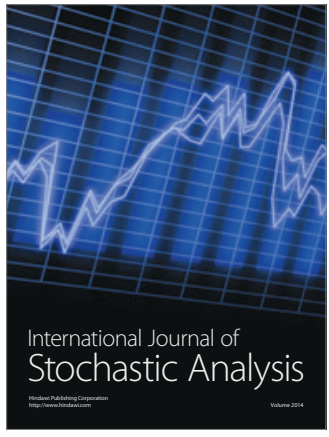

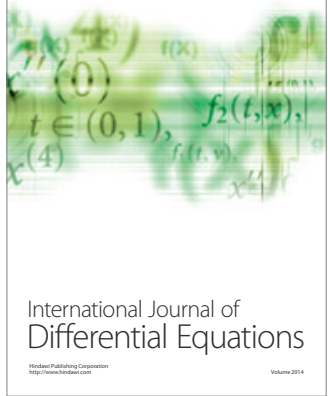
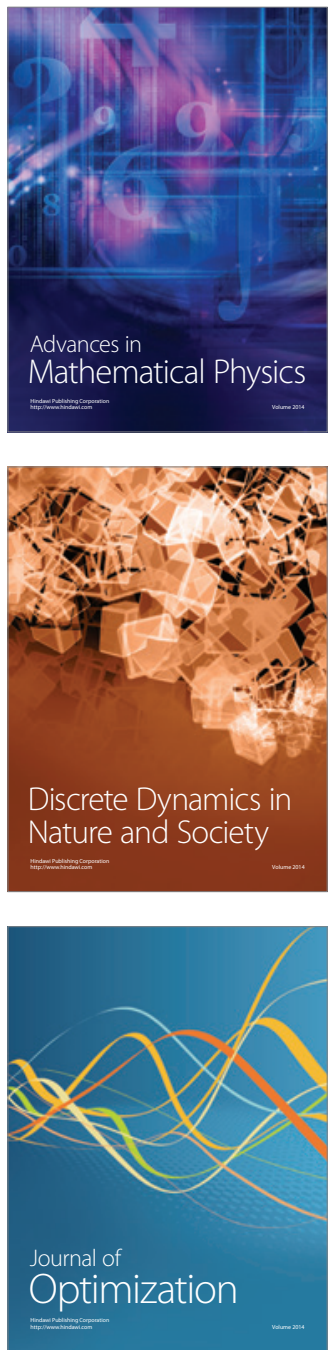